\title{
DETECTION OF NATURE OF THE FABRICATED MATERIAL BY UPSET FORGING: AN EXPERIMENTAL AND SIMULATION STUDY
}

\section{CH. L. ASLESHA, U.S. RAMAKANTH \& RAJARATNA KUMAR. V}

Associate professor, Mechanical Department, Viswanadha Institute of Technology and Management, Visakhapatnam, Andhra Pradesh, India

Associate professor, Mechanical Department, Srinivasa Institute of Engineering and Technology, Amalapuram, Andhra Pradesh, India

Associate professor, Mechanical Department, Viswanadha Institute of Technology and Management,

Visakhapatnam, Andhra Pradesh, India

\begin{abstract}
The preforms are made by taking the aluminum alloy 7075 and filling the $\mathrm{SiC}$, fly ash and graphite reinforcement particles at different Wight percentages (6, 9 and 12)using a stir casting method.The casting performs are machined using conventional lathe machine and different types of cross sections like solid, flange, ring and taper samples are prepared. These samples are tested on UTM and found mechanical compressive properties Max Compressive Strength (MPa), Max Compressive Strain and Young's Modulus (MPa). The axial, compressive and hydro static stress are found using standard analytical equations and same results are validated in ANSYS software, the analytical and ANSYS results are matched very closely. The strength co efficient and strain hardening exponent tell the plastic behaviour of the fabricated performs. For taper and ring type cross section perform samples of 12 weight \% of MMC having more ductile compare to other cross sections and other weight \% of MMC (6, 9 and base material). And compressive strength is good for the composites compare to the base material AA 7075.

KEYWORDS: AA 7075, UTM, Reinforcements, ANSYS \& Plastic Behaviour
\end{abstract}

Received: Jun 06, 2020; Accepted: Jun 26, 2020; Published: Jun 30, 2020; Paper Id.: IJMPERDJUN2020149

\section{INTRODUCTION}

Many investigators have investigated the behaviour of solid cylindrical specimens during cold offset forging due to its huge technical relevance in metal forming process. A comprehensive review of the same has been published by Johnson and Mellor [1]. Another important aspect of axis-symmetric compression from the viewpoint of testing the manufacturing properties of metal is its estimation of forming limits up to plastic instability and subsequently fractures as explained by Shaw and Avery [2]. In upsetting process, the presence of frictional constrains between the work-piece and the material haspertinent effect on the plastic deformation of the former. When a solid specimen (cylinder/square billets/rectangular billets) undergoes axial compression between the bottom and punch plate, the work-piece which is in contact with the plate surfaces undergoes heterogeneous deformation which results in the phenomenon of "barrelling" of the specimen.Friction at the faces of contact of specimen and workpiece causes a retarding effect on the plastic flow of material on the surface and its vicinity. As a result, a conical wedge like crevice of relatively un-deformed metal is formed directly below thepoint of compression while the rest of the specimen suffers high strains and bulges out in the form of a barrel. This demonstrates that the metal travels 
very easily towards the nearest free surface which is called as the point of least resistance, a well-versed principle of plastic deformation. However, the use of lubricants hugely reduces the degree of bulging and under the condition of proper ideal lubrication, bulging can be brought down to zero theoretically. The friction cannot be eliminated completely during upset forging and it is necessary to go for a correction factor for the bulging process during the designing of a die. Kulkarni and Kalpakjian [3] examined the arc of barrel, led to an assumption that it may be circular or parabolic in cross section.Meanwhile, Schley et.al [4] presented a comprehensive report on the varied geometrical factors that affect the size and shape of the barrel. Banerjee and Narayanasamy et al. [5-6] showed theoretically that barrelling radius can be expressed as a function of strain (axial) and subsequently confirmed above said through experimental analysis. Yang et al. [7] developed an upper bound theory to determine the forging load and deformed bulged profile while upset forging cylindrical billets under the dissimilar varied frictional conditions at flat die surfaces. Chen \& Chen et.al [8] developed a theoretical solution for prediction of flow stresses during an upsetting operation with consideration of the barrelling effect.Gokler et.al [9] made a comprehensive study of taper upset forging using elastic plastic FEA (finite element analysis). Narayanasamy and Pandey [10] studied the effects of barrelling of aluminium solid cylinders in cold upsetting. Malayappan and Narayanasamy [11] had experimentally analyzed the barrelling phenomenon under different frictional conditions at with introduction of an extrusion die constraint at one. Uppada Rama Kanth, Putti Srinivasa Rao and Mallarapu Gopi Krishna [4-6] stated that the improved Al-Zn / Fly Ash / SiC compounds are manufactured by a vortex method using a casting path. This article indicates that an evaluation of the microstructure and mechanical behavior of aluminum and zinc reinforced $\mathrm{SiC}$ ash and alloys was investigated. Incorporation of fly ash particles improved hardness and tensile properties, such as final stress and yield strength, improving by adding $\mathrm{SiC}$ particles and also discussing corrosion and corrosion properties.PJ Kumar et.alrefers to the experimental study of the use of vegetable oil as a cutting fluid in the manufacture of EN 353 steel ingots to reduce the cutting temperature under different lubrication conditions, that is, dry, flood and minimum lubrication conditions for quantity. Metallic models for the automotive industry, the prototype test and research laboratories are described in detail. Finally, this review provides an overview of the future automotive industry through metallic models [9-10].

\section{EXPERMENTAL WORK-PREFORMS FABRICATED BY STIR CASTING METHOD}

Primary formations are made using the Stircasting method, using cast iron dye, inert gas, electric stirrer, and crusuble made of graphite. SiC, Fly Ash and graphite particles are taken as different weight percentages with respect to the base material AA7075 as shown in the table1 and hybrid composites are made.The melting temperature of AA7075 is about $900{ }^{\circ} \mathrm{C}$. The fly ash and graphite powder are poured into the graphite crusuble and spin at a constant speed for at least 5 minutes, and it is rotated with an electric stirrer. The molten metal is poured into the cast iron dye, then the necessary samples are made as shown in Figure 1.

Table 1: Compositions of Hybrid Composite

\begin{tabular}{|c|l|c|c|c|}
\hline S. No & \multicolumn{1}{|c|}{ Composition of Reinforcements } & SiC Wt. \% & Fly Ash Wt.\% & Graphite Wt.\% \\
\hline 1 & $\mathrm{AA} 7075$ & 0 & 0 & 0 \\
\hline 2 & $\mathrm{AA} 7075+3 \% \mathrm{SiC}+1.5 \%$ Fly ash + 1.5\%Graphite & 3 & 1.5 & 1.5 \\
\hline 3 & $\mathrm{AA} 7075+3 \% \mathrm{SiC}+1.5 \%$ Fly ash + 1.5\%Graphite & 4.5 & 2.25 & 2.25 \\
\hline 4 & $\mathrm{AA} 7075+6 \% \mathrm{SiC}+3 \%$ Fly ash + 3\%Graphite & 6 & 3 & 3 \\
\hline
\end{tabular}



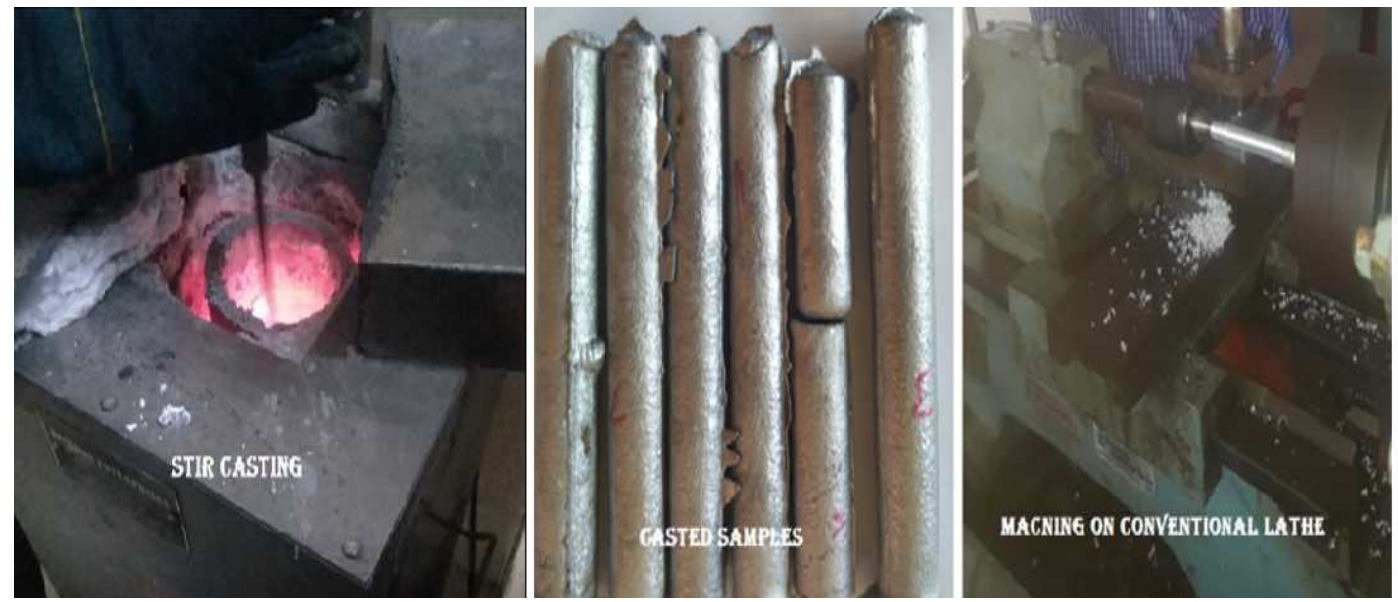

Figure 1: Stir Casting and Casted Cylindrical Samples.

\subsection{Deformation Test on UTM}

The deformation test was conducted on UTM upto shear failure or $50 \%$ of reduction in height of the samples. Taper,flange,H / D ratio 1.0 and 1.5 cross section samples are tested on this UTM machine. The load and displacement values are taken for all the samples of varius cross sections and all the mmcs and base alloys. Place the samples carefully to maintain the cental axis of the top and bottom die of the UTM.

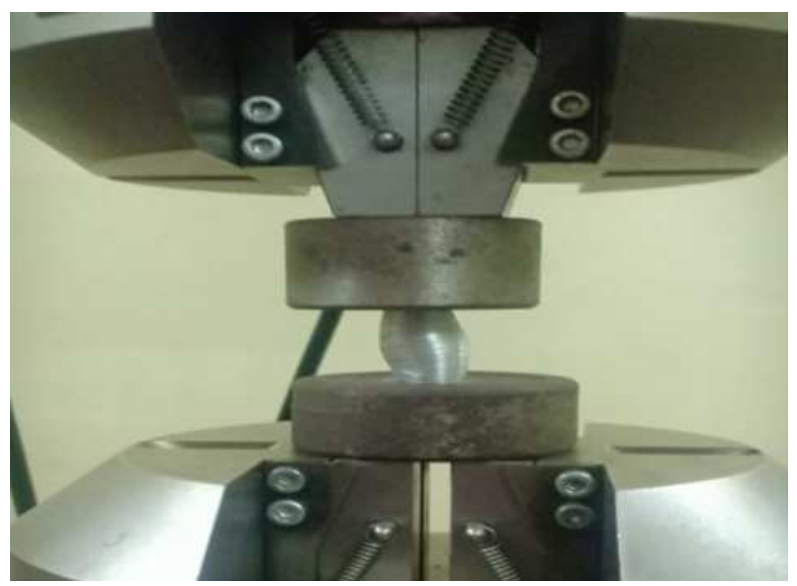

Figure 2: Compression Test on UTM.

Table 2: Compressive Properties

\begin{tabular}{|c|c|c|c|c|}
\hline S. No & $\begin{array}{c}\text { Geometrical } \\
\text { shape }\end{array}$ & $\begin{array}{l}\text { Max Compressive } \\
\text { Strength (MPa) }\end{array}$ & $\begin{array}{c}\text { Max Compressive } \\
\text { Strain }\end{array}$ & $\begin{array}{l}\text { Youngs Modulus } \\
\text { (MPa) }\end{array}$ \\
\hline \multirow{4}{*}{ AA 7075} & HD1 & 390.01 & 0.06 & 12131 \\
\hline & HD1.5 & 345.12 & 0.08 & 11232 \\
\hline & TAPER & 324.25 & 0.09 & 10132 \\
\hline & RING & 300.05 & 0.1 & 10245 \\
\hline \multirow{4}{*}{$\begin{array}{l}\text { AA7075 } \\
+6 \mathrm{MMC}\end{array}$} & HD1 & 499.03 & 0.09 & 15712 \\
\hline & HD1.5 & 323.93 & 0.1 & 13152 \\
\hline & TAPER & 489.44 & 0.2 & 10561 \\
\hline & RING & 376.91 & 0.17 & 10489 \\
\hline \multirow{4}{*}{$\begin{array}{l}\text { AA7075 } \\
+9 \mathrm{MMC}\end{array}$} & HD1 & 503.05 & 0.09 & 16536 \\
\hline & HD1.5 & 498.79 & 0.15 & 6140 \\
\hline & TAPER & 496.84 & 0.16 & 9548 \\
\hline & RING & 349.67 & 0.18 & 8433 \\
\hline AA7075 & HD1 & 495.91 & 0.09 & 14416 \\
\hline
\end{tabular}




\begin{tabular}{|l|l|l|l|l|}
\multirow{3}{*}{$+12 \mathrm{MMC}$} & HD1.5 & 496.87 & 0.14 & 11266 \\
\cline { 2 - 5 } & TAPER & 470.18 & 0.24 & 9420 \\
\cline { 2 - 5 } & RING & 413.19 & 0.21 & 8317 \\
\hline
\end{tabular}

\section{ANALYTICAL METHODS}

Triple stress was found for the plastic analysis of MMC of base alloy AA7075 and compounds using the traditional plastic analysis theory. Calcucalte the engineering streess and engineering strain values using load and displacement data given by the UTM. After that found the true streess and true strains in axial and circumferencial directions.

The strain in Axial direction $\varepsilon \mathrm{Z}=\ln \left(\frac{H f}{H 0}\right)$

Fit the true stress and strain data in hollow man power law of equation for finding the strength coefficient and are strain hardening exponents of the samples of various cross sections and made of base alloy AA 7075 and mmcs.

$$
\sigma 0=K \in^{\mathrm{n}}
$$

Here $\mathrm{K}$ and $\mathrm{n}$ are the strength coefficient and strain hardening exponents.

Hydro Static stress can be found using the formula $\sigma_{\mathrm{H}}=\frac{\sigma_{Z}+\sigma_{\theta}+\sigma_{r}}{3}$

Here $\sigma_{z}, \sigma_{\theta}$, and $\sigma_{r}$ is axial, circumferential and radial stress respectively. Axial Stress $\sigma_{z}=\sigma 0\left[\left\{1-\left(\frac{1+2 \alpha}{2+\infty}\right)\right.\right.$ $\left.\left.+\left(\frac{1+2 \alpha}{2+\alpha}\right)\right\}^{2}\right]^{-1 / 2}$, here $\propto$ is the slope between the axial and peripheral deformation and $\sigma 0$ is the flow stress of the material.

The hoop stress $\sigma_{\theta}=\sigma_{z}\left[\left(\frac{1+2 \alpha}{2+\alpha}\right)\right]$ and in radial direction stress is zero because on the free surface of the material.The table 3 showed the Strgenth coeffcient $(\mathrm{K})$ and strain hardening exponent (n) values of all varierty of cross sections of base and composite materials.

Table 3: Effect of $K$ and $N$ Values

\begin{tabular}{|l|l|c|c|}
\hline \multicolumn{1}{|c}{ S. No } & Geometrical Shape & K & n \\
\hline \multirow{4}{*}{ AA 7075 } & HD1 & 459.43 & 0.64 \\
\cline { 2 - 4 } & HD1.5 & 364.30 & 0.43 \\
\cline { 2 - 4 } & TAPER & 522.21 & 0.56 \\
\cline { 2 - 4 } & RING & 580.40 & 0.67 \\
\hline \multirow{4}{*}{ AA7075 +6MMC } & HD1 & 1109.54 & 0.77 \\
\cline { 2 - 4 } & HD1.5 & 3452.31 & 1.29 \\
\cline { 2 - 4 } & TAPER & 1148.14 & 0.73 \\
\cline { 2 - 4 } & RING & 755.89 & 0.64 \\
\hline \multirow{5}{*}{ AA7075 +9MMC } & HD1 & 1362.66 & 0.85 \\
\cline { 2 - 4 } & HD1.5 & 1214.03 & 0.77 \\
\cline { 2 - 4 } & TAPER & 1730.73 & 0.85 \\
\cline { 2 - 4 } & RING & 753.25 & 0.71 \\
\hline & HD1 & 1666.87 & 0.88 \\
\cline { 2 - 4 } & HD1.5 & 2479.47 & 0.89 \\
\cline { 2 - 4 } & TAPER & 851.17 & 0.69 \\
\cline { 2 - 4 } & RING & 821.55 & 0.69 \\
\hline
\end{tabular}

\subsection{Finite Element Simulation of Cold Upsetting Process}

Upsetting is most broadly utilized metal framing marvels for assembling of various machine segments. According to viewpoint proportions the samples are desined in ANSYS APDL, the investigation was performed with the assistance of 
solid 182 element and contanct elements 182 and 183.The contant pair was created using contancts elements.The material properties of top and base passes on of the UTM machine was thought to be steel(E=210Gpa, $\mu=0.3)$ and the readied tests are AA7075and their composites.

\section{RESULTS AND DISCUSSIONS}

\subsection{Compressive Strength}

The compressive strength is high for $\mathrm{H} / \mathrm{D}$ ratio 1.0 for all MMCs compare to the other cross sections as shown in figure 3 to 4 . The reason for high strength is the short length performs will takes more force than other cross sections.

The compressive strength of AA7075 + 9mmc alloy was more for H / D 1.0, 1.5 and Taper cross sections compare to other mmc's of alloys as shown in Figure 4.
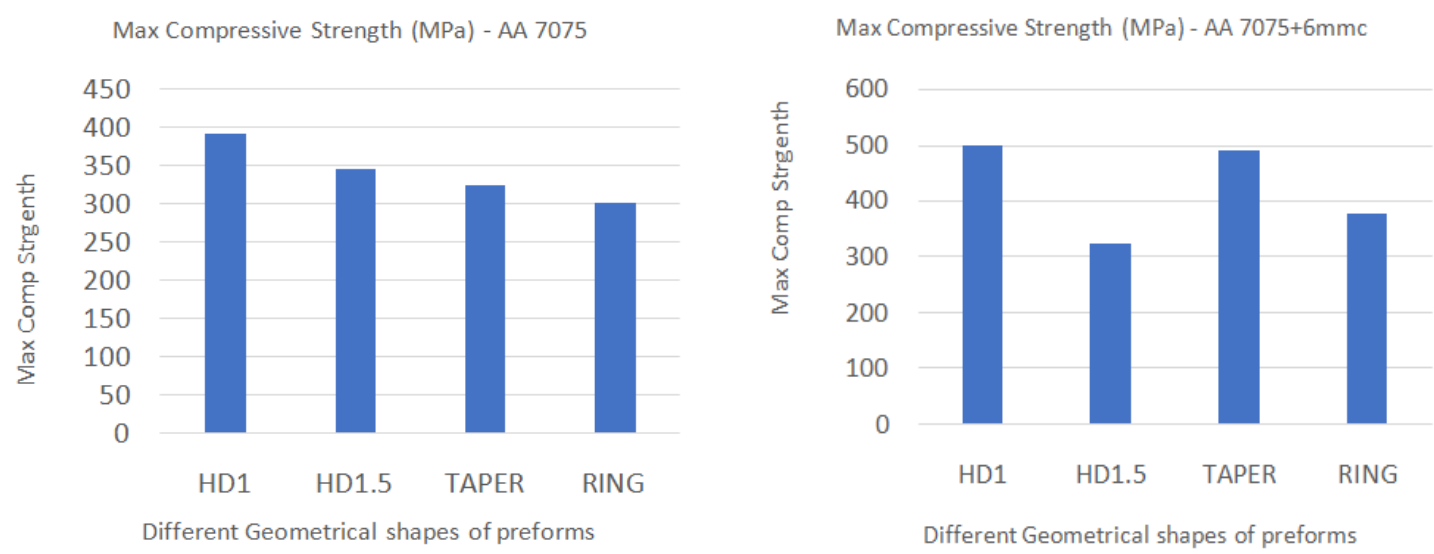

Figure 3: The Compressive Strength of AA 7075 and AA7075+6 Mmc.
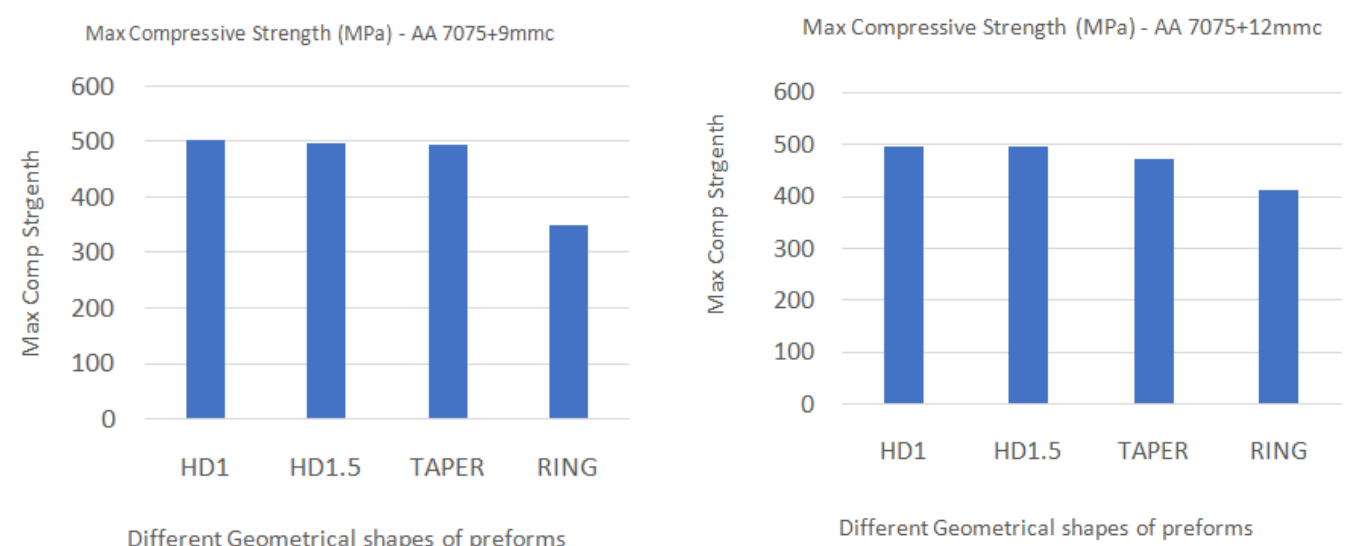

Different Geometrical shapes of preforms

Different Geometrical shapes of preforms

Figure 4: Compressive Strength of AA $7075+9$ Mmc and AA7075+12 Mmc.

\subsection{Ductile Nature of Performs}

Figure 5 shows the ring type cross section shows the good plastic behaviour compare to other cross sections as show in Fig 5 for mmc's and alloys. The axial stress is increased for the H / D ratio 1.0 of composite metal matrix composites compare to base alloy AA7075 whereas for AA7075 + 9MMC composite very close to the effective strain line compare to other composites and base alloy it indicates the good ductile properties are presented. $\mathrm{H} / \mathrm{D}$ ratio 1.5 the hoop stress is increased for 9 and $12 \mathrm{MMC}$ compare to $6 \mathrm{MMC}$ and base alloy it indicates that they are exhibit the good plastic properties. 


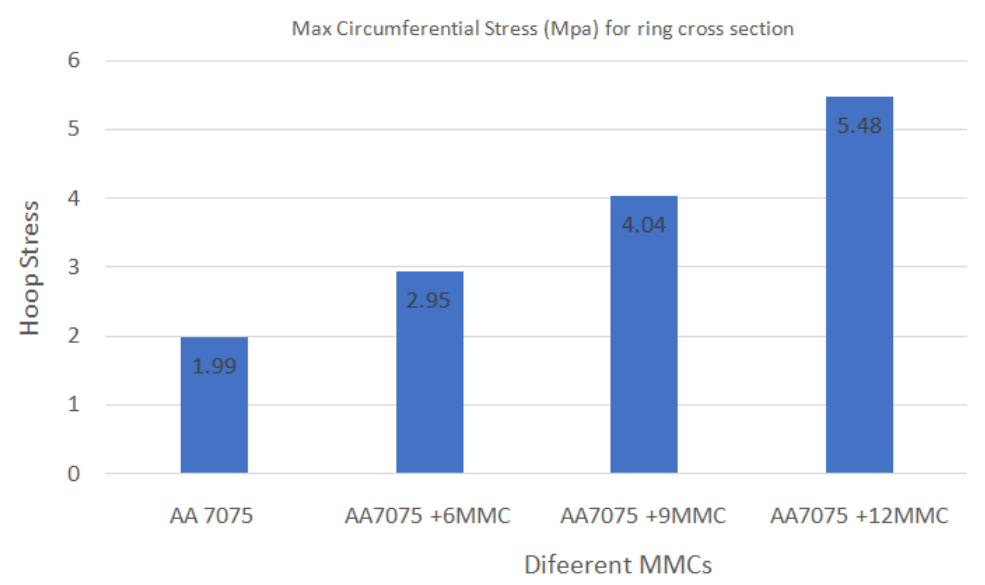

Figure 5: Max Circumferential Stress (MPa) for Ring Type Cross Section.

\subsection{Effect of $K$ and $n$ Values}

The $\mathrm{K}$ and $\mathrm{n}$ values are high for solid cross section for the $6 \mathrm{MMC}$ material it indicates the $6 \mathrm{MMC}$ material having the good ductility properties compare to other cross sections and others MMCs. The $\mathrm{K}$ and $\mathrm{n}$ values are increased with increasing of reinforcements. Hence the composite system gives the better results compare to the base material AA7075.

\subsection{FEM Results}

The maximum displacements results of various preforms are obtained in ANSYS software are equal to the experimental results, a good agreement was shown between them.
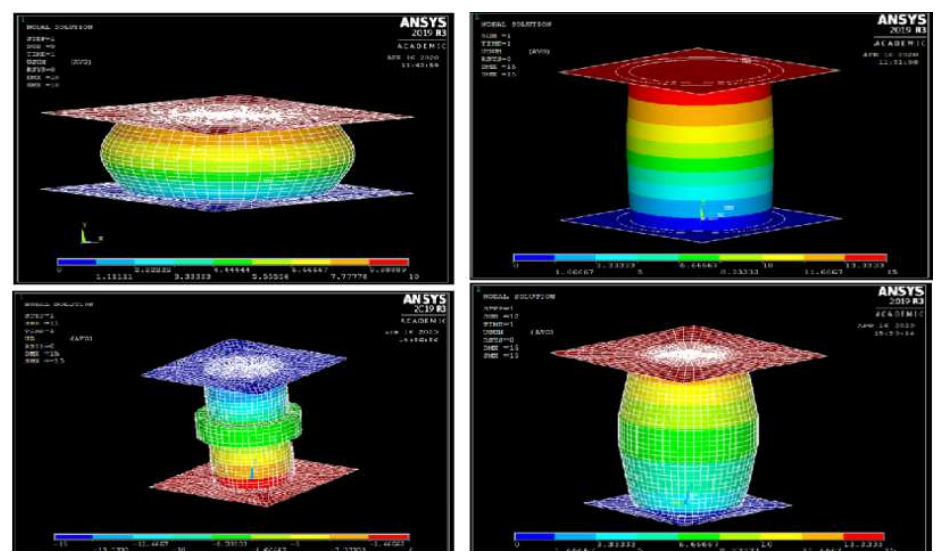

Figure 6: Max Displacements of Different Cross Section in ANSYS.

\section{CONCLUSIONS}

The Following Conclusions are made for Estimating the Nature of the Material:

- The preforms are manufactured using stir casting technique.

- The compressive strength is $22.46 \%$ is more for AA7075+9mmc of H/D ratio 1.0 compare to the base alloy AA7075 of H/D ratio 1.0.

- Max Circumferential Stress is $63.68 \%$ is more for ring type cross section of AA7075+12mmc compare to the base alloy AA7075. 
- The ANSYS software was used to determine the stress for analysing the plastic flow of the material and the results are validated and are very close victim to each other.

- Results obtained by finite element analysis closely related to experiment results. The values are thus validated by the FEM model.

\section{FUNDING ACKNOWLEDGEMENT}

Thanking you for supporting this research work by our VITAM and SIET management

\section{REFERENCES}

1. Johnson W, Mellor PB (1975) Engineering plasticity. Van Nostrand, London, Ch. 6, pp 110-114.

2. Shaw C, Avery JP (1980) Forming limits - reliability, stress analysis and failure prevention methods in mechanical design. Century, Chicago, IL, ASME, pp 297-303.

3. Kulkarni M, Kalpak Jian S (1969) A study of barreling as an example of free deformation. ASME J Eng. Ind 91:743-754.

4. Schley A, Veneer TR, Takomana SL (1982) Shape changes in the upsetting of slender cylinders. ASME J Eng. Ind 104:79-83.

5. Banerjee Barreling of solid cylinders under axial compression. ASME J Eng. Mater Tech 107:138-144 48.

6. Narayanasamy, Murthy RSN, Viswanatham K, Chary GR, Prediction of the barreling of solid cylinders under axial compressive load. J Mech Work Tech 16:21-30.

7. Yang Y, Choi Y, Kim JH (1991) Analysis of upset forging of cylindrical billets considering the dissimilar frictional conditions at two flat die surfaces. Int J Mach Tools Manuf 31:397-404.

8. Chen, Chen CJ (2000) on the non-uniform deformation of the cylinder compression test. J Eng. Mater Tech Trans ASME 122:192-197.

9. Gokler MI, Darendeliler H, Elmaskay NE (1999) Analysis of tapered preforms in cold upsetting. Int J Mach Tools Manuf 39:1-16.

10. Narayanasamy R, Pandey KS (1997) Phenomenon of barrelling in Al solid cylinders during cold upset-forging. J Mater Proc Tech 70: 17-27.

11. Malayappan S, Narayanasamy $R$ (2003) some aspects of barrelling in aluminium solid cylinders during cold upset forging using die with a constraint. J Mater Process Technol 135:18-29.

12. Uppada Rama Kanth, Putti Srinivasa Rao, Mallarapu Gopi Krishna, "Mechanical behaviour of fly ash/SiCparticlesreinforced Al-Zn alloy-based metal matrix composites fabricated by stir casting method”, JMRT Vo l. 201 9; 8(1):737-744.

13. U. S. Ramakanth \& Putti. Srinivasa Rao, "Wear Behaviour of Al 7075/Fa/Sic Hybrid Composites", International Journal of Mechanical and Production Engineering Research and Development (IJMPERD) ISSN (P): 2249-6890; ISSN (E): 2249-80 Vol. 9, Issue 2, Apr 2019, 331338.

14. U.Ramakanth, Putti Srinivasa Rao, "Corrosion Studies on Ceramic Particulates Reinforced Hybrid Metal Matrix Composites" International Journal of Mechanical Engineering and Technology (IJMET) Volume 10, Issue 01, January 2019, pp. 661-666, ISSN Print: 0976-6340 and ISSN Online: 09766359.

15. Addanki Venkata VishnuP. Jamaleswara Kumar, "Experimental Investigations in Turning of Steel Alloy Under Different Lubrication Conditions" Recent Advances in Material Sciences pp 257270.

16. AK Matta, SP Kodali, J Ivvala, PJ Kumar, "Metal Prototyping the future of Automobile Industry: A review", Materials today proceedings Volume, 2018, Pages 1759717601. 
17. KC, VISHWANATH. "INVESTIGATION OF EFFECT OF FRICTION STIR DRILLING PARAMETERS ON ELASTOPLASTIC BEHAVIOUR OF AL ALLOY." International Journal of Mechanical and Production Engineering Research and Development (IJMPERD) 8.1 (2018):10591064.

18. REDDY, A. CHENNAKEESAVA. "Low and High Temperature Micromechanical Behavior of BN/3003 Aluminum Alloy Nan composites." International Journal of Mechanical Engineering (IJME) 6.4 (2017): 2734.

19. Roy, Samanwita. "COMPARATIVE FLOW ANALYSIS OF NACA S6061 AND NACA 4415 AEROFOIL BY COMPUTATIONAL FLUID DYNAMICS." International Journal of Mechanical Engineering (IJME) 7.2 (2018):918.

20. Krishnaveni, J., G. Sowmya, and U. Sudhakar. "Thermal Analysis of Cylinder Head by Using Finite Element Analysis." International Journal of Mechanical Engineering (IJME) 3.6 (2014): 1120.

21. REDDY, P. VENKATESHWAR. "MECHANICAL PROPERTIES OF GLASS/BAMBOO FIBERS REINFORCED EPOXY COMPOSITES COMPARING WITH CHOPPED STRAND MAT TREATED WITH BACTERIAL CELLULOSE." International Journal of Mechanical and Production Engineering Research and Development (IJMPERD) 8.5 (2018):16.

22. SINGH, S. PRATHAP, et al. "INVESTIGATION OF TENSILE PROPERTIES OF ALKALI TREATED ANDANUS ODORATISSIMUS FIBER REINFORCED WITH POLYMER MATRIX COMPOSITE." International Journal of Mechanical and Production Engineering Research and Development (IJMPERD) 8 Special Issue 8 (2018):403407.

23. VIJAYAN, R., A. KRISHNAMOORTHY, and M. ARAVINDHAN. "TESTING THE WEAR CHARACTERISTICS OF NATURAL FIBER COMPOSITE." International Journal of Mechanical and Production Engineering Research and Development (IJMPERD) 8.3 (2018):785790.

24. Sharma, Nikita, and B. Jena. "Behaviour of Flyash Brick Masonry Columns." International Journal of Civil Engineering (IJCE) 6.1 (2017): 914. 